\title{
The Effect of Using a Strategy Based on Digital Storytelling on Developing Primary School Pupils' English Speaking Skills
}

\section{Dr. Mohamed Farrag Badawi}

Faculty of Education, October 6 University

\section{Dr. Neveen Mohamed El Gabas}

Faculty of Education, Hilwan University

\section{Nour Elhoda Ali Mohamed}

MA Candidate Faculty of Education, October 6 University

\section{Abstract:}

ome primary school pupils lack the ability to
speak English. The study investigated the effect
of using digital storytelling strategy on developing primary school students' English-speaking skills. The study used a quasi-experimental approach. The study recruited 60 pupils; 30 pupils for the experimental group and 30 pupils for the control group. While the experimental group pupils were exposed to storytelling strategy, the control group pupils received regular speaking classes. A speaking skill test was developed and administered. Results showed that the pupils of the experimental group outperformed the control group in post-treatment. The experimental group pupils' oral performance increased after exposing them to different storytelling activities. In storytelling, pupils are encouraged to join in repetitive sentences and have the opportunity to suggest variations in certain elements and aspects of the story.

Keywords: EFL Speaking skills, Digital Storytelling, interaction, performance, transaction.

\section{Introduction}

The advancement of technology has led to wider use of technology in the educational process. Technology has become available to both teachers and students. Modern 
technologies have allowed teachers to enhance their knowledge, skills, and their language instruction. It is noted that educational curricula in the Arab world need continuous development to keep pace with learners' needs and thus link these curriculums to students' lives. Meanwhile, current teaching methods focus mainly on route memorization and rehabilitation, not on comprehension and creativity. It is therefore important to integrate modern technology in educational settings.

According to Amani Yamani (2019), student's capabilities and skills can be developed using modern technology during the different educational stages. This explains the importance of using modern technology in the right way to help students improve their English-speaking skills by using digital media. Therefore, there are many examples such as audio and video fusion, as well as photos in the teaching of educational curricula that help students properly pronounce and configure English sentences

Since English is the international medium pf communication, learning English has become a critical issue throughout all educational levels; the major educational objectives regarding learning English as a second language are to respond to public life situations appropriately and to be able to express enough opinion and expression. Toward this end, modern technology has helped develop learning English language skills in general and speaking skills. Speaking is defined as the ability to develop oral skills and mastery and includes the ability to negotiate and manage dialogues (Abdel Fattah, 2006, P. $30)$. 
Joe and Burns (2012, PP. 151-152) identified four categories of speaking skills: a) correct pronunciation; b) function of speech; c) interaction management including role distribution and conversation organization as well as the use of verbal and nonverbal language, and d) The organization of speech which includes the creation of objectivity, unity, and consistency of the meanings through the language structures and the choice of words (Goh and Burns).

Traditionally, researchers have divided the skill of speaking into three sections: 1) mechanics (pronunciation, grammar, and vocabulary), 2) jobs (trading and interaction), and 3) social and cultural bases (speech pace, the duration of breaks between speakers, the relative roles of the participants) considering the speakers and speaking purposes (Marriam et al., 2011, PP. 38- 39).

There are many strategies that can be used to develop speaking skills, one of which is digital storytelling. Since ancient times, storytelling has been used as a means of communicating and transmitting traditions heritage and history to future generations and has grown with continuous technological development and has been implemented in the educational process. To this day, people continue to tell and display stories using modern technology. We now use digital techniques of storytelling stories. In this sense, storytelling is generally a strong educational strategy that can be used to enhance the results of public education. As Armstrong (2003) and Sharda (2010) highlighted, computers, digital cameras, editing software and other technologies become more 
readily available in the classroom, so they provide learners and teachers the tools needed to create digital stories more easily than ever.

The picture and music language help students connect and maintain their enthusiasm for learning. In his article entitled "Digital Narrative Narration,", Robin (2008) pinpointed that as an effective technological tool of the 21 st century digital storytelling is part of our lives and has become an important part of teaching and learning, where digital storytelling is one of the innovative educational strategies that can engage students in purposeful education.

Digital storytelling is defined as a short story that is prepared in the form of a 2-3-minute-long video, in which the storyteller uses photos and sound to tell his or her story using programs and digital devices to view photos and movies. The story can be linked to others, or place or objective, or anything that gives a personal touch to the story. While Multimedia enhances visual communication the process still includes story planning, writing, modifying, clarifying and production to make communication more effective (Norman, 2011, P.12).

Several studies have shown that digital storytelling is an effective tool to make educational environments more attractive and exciting. Hence, this strategy helps improve student participation and provide learners with better learning outcomes (ACARA, 2013). For instance, Mariana (2018) showed that digital storytelling integrates multiple 
methods of expression through language, symbols and means of presentation, where allowed digital technology and the possibility of creating interactive ways of digital storytelling online using Web tools 3.0. In the same vines, in Egypt, Abdelmageed (2018) employed online digital storytelling with university students to enhance their speaking skills. To that end, he used the interactive website "WeVideo" that has a library of images and background music. He found that digital storytelling improved students' speaking proficiency in terms of fluency and pronunciation.

The merits of using digital storytelling can enrich the educational process led researchers to continue analyzing the various uses of digital storytelling in the classroom. For instance, Carmen's study (2014) integrated fifty digital stories that focused on previously selected topics such as violence, racism and war, and Makosa's study (2013) indicated that using digital technology is more enjoyable for learners than the traditional method and that learners are more intrigued by teaching methods using multiple digital technology.

\section{Research Problem}

Some primary school students lack the ability to speak English inside classrooms. It may be due to some shortages of class activities that encourage them to speak English. It is planned to employ digital storytelling as a means of developing primary school students' Englishspeaking skills. 


\section{Research Questions}

The current research seeks to answer the following questions:

What is the effect of using digital storytelling strategy on developing primary school students' skills?

\section{Hypotheses}

- There are statistically significant differences between the mean scores of the experimental group students in the pre- and post-measurement of English-speaking skill and its sub-dimensions in favor of the post-measurement".

\section{Delimitations:}

The research is delimited to:

- Time limits: will be applied in the second semester of the academic year 2019-2020.

- Spatial limits: Will be applied in Giza Governorate.

- Human Boundaries: a sample of sixth graders at the primary level.

- Thematic limits: digital storytelling and Englishspeaking skills suitable for primary school students.

\section{Research Significance}

This research may lead to:

- The effective use of modern digital technology for students in a positive and much more enjoyable way than traditional methods, hence overcoming the problems and challenges faced by primary school pupils and their ability to speak and express English. 
- Curriculum designers may integrate digitals storytelling for primary school students to raise their language awareness.

- Helping teachers understand the value of digital storytelling in raising students' awareness and motivating students to learn and speak English.

\section{Review of literature}

\section{Speaking Skills}

According to the Linguistics Application Center, speaking is a skill to communicate effectively with others and includes selecting words that suit the topic and the listener, paraphrasing, providing feedback, changing the direction of dialogue, clarifying, using body language and facial expressions, and where to speak as to reach the audience with the highest level of understanding and attract attention. In the current study, speaking is the response of primary school students in Egypt in an appropriate manner and participation in conversations in a convincing manner without stuttering, and using full sentences and expressing knowledge of a wide range of vocabulary.

Aprianto and Zaini (2019) argue that every language has skills that are integrated. As one of the four language skills, speaking is vital for language teaching and learning; however, it is obvious that oral skills are not taught intensively in language classrooms mainly because they are not included in tests, so teachers tend not to use precious class time for oral production while giving priority to teaching grammar, written, or reading skills (Corbett, 
2003). Goh and Burns (2012) confirm that vitality of speaking as an essential language communication skill and that its importance to language learners goes beyond just day-to-day communication. Speaking can facilitate language acquisition and contribute towards the academic development of many second language learners. Teaching speaking skills also faces some problems that are not related to the fact that some teachers feel uncertain about their spoken language proficiency and avoid speaking the target language in class and provides few opportunities for the students to speak in class but spring from the condition that some students may be afraid of making mistakes and being criticized (Pakula, 2019).

\section{Speaking Functions}

It is noted that communicative competence emphasized the importance of the rules for appropriate use, or communicative form and function in integral relation to each other being important for the function of speaking skills (Katherine, 2017). To master speaking skills in English is a priority for many second and foreign language learners that is why several language experts have attempted to categorize the functions of speaking in human interaction. The classification of speaking as a function can be shown in two main aspects. They are interactional and transactional functions. The pedagogical implications for planning, implementing, and evaluating speaking activities are the ways to illustrate the specific characteristics of both functions to identify the differences between them and how to analyze them. 
Brown and Yule (1989) urge that the interactional language is mainly listener-oriented because its main concern is how to reshape social relationships. They declare that the interactional chats are considered shifting topics with a great deal of agreement on them, where speakers, in such conversations, do not challenge each other, argue, or require repetition of something that the other person has said, since they usually end up feeling comfortable and friendly with each other. The examples of such kind of interactions are people meeting each other on a bus or train for the first time, at parties, or at the beginning of a new lecture course.

More recently, Richards (2008) uses a new version of Brown and Yule's classification of spoken language. It comprises three aspects, talk as interaction, talk as transaction, and talk as performance. Based on this classification, he provides examples of each type of talk and mentions some of the necessary skills to develop.

\section{1) Talk as interaction}

Talk as interaction refers to what is normally meant by "conversation" and describes interaction that serves a primary social function. It is noted that in these kinds of conversations, the focus is more on the speakers and how they wish to present themselves to each other than on the message. It is also noted that such exchanges may be either casual or more formal, depending on the circumstances. The daily communication remains interactional with other people. This refers to what is said to be a conversation. It is 
an interactive communication which is spontaneous by two or more persons. This is about how people try to convey their messages to other people. The main intention in this function is social relationship. The examples of this kind of talk include polite conversations, which do not seek to develop future social relationships (as in the case of adjacent passengers during a plane flight), casual conversations that serve to mark an ongoing friendship (as those chats between school friends over coffee), polite conversations reflecting unequal power between the two participants (as in the case of a student chatting to his or her professor while waiting for an elevator), or those in which people share personal recounts (like telling a friend about an amusing experience, and hearing him or her recount a similar experience he or she once had).

\section{2) Talk as transaction}

Speaking as transaction is more focused on message that is conveyed and making others understand what we want to convey clearly and accurately. In this type of spoken language, students and teacher usually focus on meaning or talking what their way to understanding. In the case of talk as transaction, this author asserts that its main features are the facts that it has a primarily information focus, it is centered on the message and not on the participants, speakers employ communication strategies to make themselves understood, there may be frequent questions, repetitions, and comprehension checks as well as negotiation and digression. He finally remarks that 
linguistic accuracy is not always important (Richards, 2008).

\section{3) Talk as performance}

In this case, speaking activities are more focused on a monolog than on a dialog. Function of speaking as performance occurs at speeches, public talks, public announcements, telling story and so on. This third type of talk refers to public talk. It is the talk which transmits information before an audience such as classroom presentations, public announcements, and speeches. Talk as performance tends to be in the form of monologue rather than dialogue such as giving a class report about a school trip, conducting a class debate, and giving a lecture. In this type, the function of speaking is to show the speaker's performances when he/she conveys the message. Talk as performance is closer to written language than conversational language (Richards, 2008). The speaker's preparation in the form of a written text before performing in front of the audience is needed. Hence, the speaker is ready to speak when he/she has the readiness of her/his mental.

\section{Teaching speaking through Culture}

English is undoubtedly a source of international communication among the people having diverse linguistic and cultural backgrounds. It has been the medium of instruction in most of the public and private sector institutes where pedagogical practices applied in a language classroom focus on lexical and grammatical aspects of learning a foreign language. In addition to 
language teaching pedagogy, the status of English as a compulsory subject is to help students receive and understand information of course books prescribed at intermediate level of education. Therefore, English as a medium of instruction tend to develop language skills of the students required to learn science through prescribed course-books of Physics, Chemistry, and Biology.

According to Emmitt et al (2003), students need to become efficient in using language for a range of purposes, such as following directions, requesting information, entertainment, and self-expression'. These needs or purposes can be fulfilled through classroom activities aiming to enhance communicative competence of the students, but the use of traditional teaching methods hardly help learners communicate language in cultural context. However, a pedagogical process may be introduced to integrate cultural awareness about using language through textbooks employed in a language class. Thus, the use of appropriate communicative teaching strategies not only raise learners' efficiency in using language but also enhance cultural awareness in communicating language in cross-cultural context.

\section{Digital Storytelling}

Digital storytelling is a 2-3-minute-long video, in which the storyteller uses his or her own voice to tell a story. The story can be associated with a person, a place, a goal, or anything that gives the story a personal touch. Norman (2011, P. 12) defined it as a valuable tool to help teachers to motivate students to participate in the discussions and 
explain the educational content. It is a new way of storytelling that uses music and other means of audio, photos, attitudes and experiences (Kosara, \& Mackinlay, 2013; Nazuk et al., 2015). Shelton et al. (2017) perceived it as storytelling with visual communication that includes vivid images with sounds.

\section{Digital storytelling in the EFL classroom}

Digital storytelling is an effective and time-saving tool that can be manipulated for various purposes within the classroom environment. It can provide teachers with an unprecedented way of presenting new information to learners (Robin, 2008). Thus, it becomes a good opportunity to avoid dull teaching cycles and spices up lessons with joy and curiosity, two crucial factors leading to learning. Besides, digital storytelling makes it possible to present abstract content in such a concrete way that students may find it easier to relate to the topic and elaborate from there (Robin, 2008). Most importantly, students might also be asked to create their own individual or collective digital stories, through which they can cater to their own learning (Sadik, 2008). Digital storytelling can be used in the classroom for a variety of purposes, and it can contribute to students in several different ways. Students can shoot videos of themselves or other people or objects; or record their voices to narrate a certain story. They can capture photographs of themselves, other people, or objects and build a story in sequences of images or photo albums. They even might draw caricatures or create comic stories through digital tools which provide them with several ready-made features. 
According to Robin and Pierson (2005), learners who take part in the making of a digital narration acquire how to organize thoughts, state their opinions on a given topic, and tell a complete story, which will improve their communication in return. On the other hand, digital storytelling gives learners chances to share with others (or an audience) what they have created. This is nothing but an opportunity to help students realize the motives behind what they are doing and feel significant in the face of connecting with others (Jakes, 2005).

\section{Digital storytelling for teaching speaking}

Many studies done to show the effectiveness of storytelling, especially with young learners, reveal that it is a successful technique yielding productive results. A study carried by Abasi and Soori (2014) investigated if storytelling had any effects in improving English vocabulary learning skills of kindergarten students in Iran. The participants were 20 children (11 girls and 9 boys in total) with average age of five. All the children were taught by the same teacher using the same textbook, which was the story of The Three Bears in this particular research. The children were given picture vocabulary tests in a pretest/post-test scheme to compare their vocabulary performances before and after the treatment. The statistical results of one-sample Kolmogorov-Smirnov test suggested that the children performed better in the post-test than they did in the pre-test, with a statistically significant increase in their mean scores. This finding suggests that storytelling is an effective way to boost the vocabulary learning skills of young learners of EFL. 
Another similar study on teaching English vocabulary by Cubukcu (2014) aimed at finding out if the technique of Total Physical Response Storytelling (TPRS), which was formed by Blaine Ray in 1988, could contribute to the lexical skills of secondary school students. The participants were 44 sixth grade secondary school students in the city of Izmir in Turkey, 22 of whom were in the control group studying the 20 target vocabulary in a text while the other half were the experiment group learning the same group of words through storytelling and personalization. When the results were analyzed, it was observed that the experiment group had significantly higher scores than the learners in the control group. Therefore, storytelling, and its component of personification, influenced the vocabulary learning skills of secondary school learners of English. The researcher also stated that TPRS was a fun way of learning vocabulary as creativity for both the teacher and the learners is in the core of this technique.

\section{Methodology}

The research used a quasi-experimental approach. The participants were placed into the corresponding levels based on the test results. Two groups of participants took part in the study as the investigated groups. One of the groups is experimental which received the treatment, i.e. the speaking skills are addressed to be developed with the implementation of digital storytelling. The other is the control group which received no treatment.

The study was conducted in an EFL context in Egypt, more specifically in El Fardous Private School. The courses are open to pupils aiming to improve their English 
language proficiency in all aspects of -language. The classes are pupil-centered and focus on developing EFL pupils' communicative skills. The course lasts for 2 weeks with 6 sessions with duration of forty minutes per session or more.

\section{Research community}

The present research study is conducted in basic education in Egypt. The total number of the participants is 60 including males and females. The experimental group consisted of 30 participants, and the same number of participants is addressed to the control group. The age of the participants ranged from 12 to 13 . The participants are placed according to the results of the pre-test that they took at the very beginning of the course. Therefore, it is implied that the pupils in both groups had the comparable levels of language proficiency.

\section{Materials}

Since the experiment is to be conducted with the participants from the same level of English, the materials in both experimental and control groups are the same. The course textbook which is used for the classes is "Time for English 6" by Susan Rivers \& Setsuko Toyama and adapted for Egypt by Nadia Touba \& Sahar Rizk under the supervision of Ministry of Education. The coursebook comprises ten units each of which focus on and covers one topic. However, during the experimental phase only the first five units ("Places we go", "In the Restaurant", "Daily Activities", "Visiting a Film Studio" and "In Town") are covered. 


\section{Instrumentation}

The study consists of speaking skills' pre-test, applying digital storytelling sessions, and speaking skills' post-test. They will be discussed as follows:

Speaking skills' pre-test is conducted with the participants of both the experimental and the control groups. The pre-test is conducted at the very beginning of the course. It is conducted with the purpose to assess the participants' speaking performance in both groups prior to the treatment to find out the initial level of the participants' speaking proficiency.

During the test, the participants are examined individually. The test is rated by two raters on the basis of an adapted analytic rubric. The examinees are recorded and graded; each rater graded them individually, and the average of the grades is calculated via SPSS. An inter-rater reliability is also conducted to find the consistency between the scores.

According to the criteria suggested by Bachman (2004), the formula for calculating the scores is the following: RS1 + RS2 = FS

where RS1 is the score given to the examinee by first rater and RS2 is the score given by the other rater, and FS is the final score. Both pre and post-tests are parallel, i.e. they had the same structure and the same level of complexity with the same content. The tests are developed according to the criteria suggested by PET Speaking Test. Accordingly, the tasks and the materials developed for the tests are adopted from this speaking test. 
The test consisted of open-ended questions aiming to create an interaction between the examiners and the examinee and make the examinee express his or her opinion or preference around a posed statement in the target language. The task aimed at assessing the examinee's fluency in expressing his or her thoughts in the target language and appropriate use of grammar, vocabulary, pronunciation, and the ability to give fully and reasonable responses. The time allocation for this task is 34 minutes.

The post-test is conducted when the treatment in the experimental group is over. It aimed at assessing the participants speaking proficiency after getting the treatment and reveal whether it had any effect on speaking or not.

The test consisted of open-ended questions aiming to create an interaction between the examiners and the examinee and make the examinee express his or her opinion or preference around a posed statement in the target language. The task aimed at assessing the examinee's fluency in expressing his or her thoughts in the target language and appropriate use of grammar, vocabulary, pronunciation, and the ability to give fully and reasonable responses. The time allocation for this task is 3 4 minutes.

\section{Results and Discussion}

The hypothesis states that "there are statistically significant differences between the mean scores of the experimental group students in the pre- and post- 
measurement of English-speaking skill and its subdimensions in favor of the post-measurement."

To verify the hypothesis, the researcher used the Paired Samples T Test to verify the significance of the differences between the mean scores of the experimental group students in the pre and post measurement of English speaking skill and its sub-dimensions. The results were as in the table (1).

Table (1): the significance of the differences between the mean scores of the experimental group pupils in the pre and post measurement of English-speaking skill and its sub-dimensions ( $N$

\begin{tabular}{|c|c|c|c|c|c|c|c|}
\hline \multirow[b]{2}{*}{$\begin{array}{c}\text { English } \\
\text { Speaking Skills }\end{array}$} & \multicolumn{6}{|c|}{$=30)$} & \multirow{2}{*}{$\begin{array}{c}\overline{\text { Effect }} \\
\text { Size }\end{array}$} \\
\hline & Test & Mean & $\begin{array}{c}\text { Std. } \\
\text { Deviation }\end{array}$ & $\begin{array}{c}\text { T } \\
\text { Value }\end{array}$ & sig & To & \\
\hline \multirow{2}{*}{ Pronunciation } & Pre & 1.87 & 0.33 & \multirow{2}{*}{14.96} & \multirow{2}{*}{0.001} & Post & \multirow[b]{2}{*}{0.885} \\
\hline & Post & $\mathbf{3 . 3 3}$ & 0.38 & & & Test & \\
\hline \multirow{2}{*}{ Grammar } & Pre & 1.94 & 0.36 & \multirow{2}{*}{11.66} & \multirow{2}{*}{0.001} & Post & \multirow[b]{2}{*}{0.824} \\
\hline & Post & 3.31 & 0.45 & & & Test & \\
\hline \multirow{2}{*}{ Word choice } & Pre & 1.98 & 0.37 & \multirow{2}{*}{12.17} & \multirow{2}{*}{0.001} & Post & \multirow[b]{2}{*}{0.836} \\
\hline & Post & 3.32 & 0.36 & & & Test & \\
\hline \multirow{2}{*}{$\begin{array}{l}\text { Fluency\& } \\
\text { Coherence }\end{array}$} & Pre & 1.76 & 0.56 & \multirow{2}{*}{9.88} & \multirow{2}{*}{0.001} & Post & \multirow[b]{2}{*}{0.771} \\
\hline & Post & 2.94 & 0.28 & & & Test & \\
\hline \multirow{2}{*}{ Skill } & Pre & 2.13 & 0.32 & \multirow{2}{*}{16.84} & \multirow{2}{*}{0.001} & Post & \multirow[b]{2}{*}{0.907} \\
\hline & Post & 3.55 & 0.27 & & & Test & \\
\hline \multirow{2}{*}{ Total } & Pre & 9.69 & 1.14 & \multirow{2}{*}{27.69} & \multirow{2}{*}{0.001} & Post & \multirow[b]{2}{*}{0.965} \\
\hline & Post & 16.44 & 0.53 & & & Test & \\
\hline
\end{tabular}

Table (1) shows that there are statistically significant differences at the level of significance $(0.001)$ between the mean scores of the experimental group students in the pre 
and post measurement of English speaking skill and its sub-dimensions in favor of the post-measurement, and thus the third hypothesis has been achieved.

The researcher also calculated the effect size for the independent variable - the strategy based on digital storytelling - on the dependent variable - English speaking skills - the effect size was strong for all sub-skills or the total score of the test, whose value ranged between ( 0.77 0.96 ), according to the reference table for the levels of the effect size in the range: from zero to less than 0.3 weak effect, from 0.3 to less than 0.5 medium effect, and from 0.5 to one true strong effect (Ikhlas Abdel Hafeez, Mustafa Bahi, Adel Al-Nashar, 2004, p. 235).

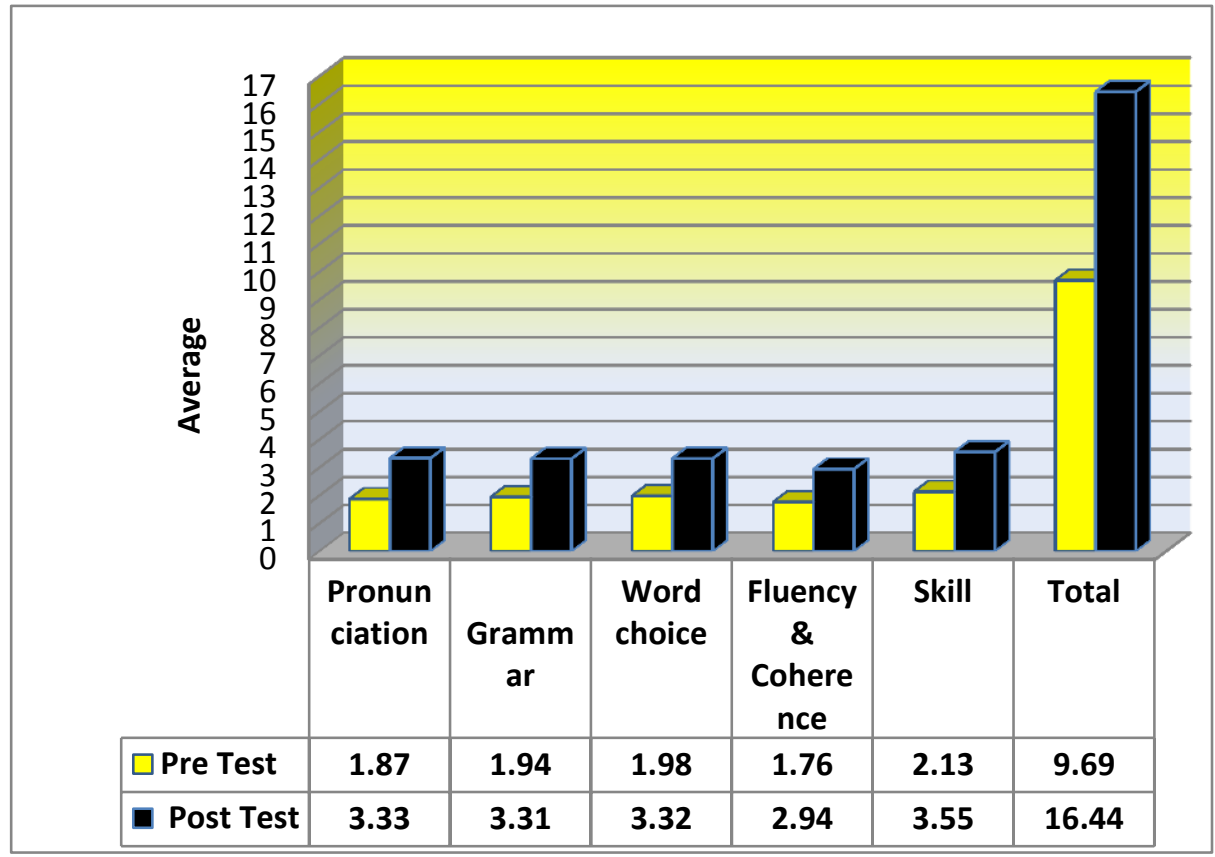

Figure (1) shows the mean scores of the experimental group pupils in the pre and post measurement of English speaking skill and its sub-dimensions. 
Figure (1) shows the mean scores of the experimental group pupils in the pre and post measurement of English speaking skill and its sub-dimensions.

In view of the possibility of attributing the result of the previous hypothesis to other factors besides the training received by the students of the experimental group, such as maturity and previous experience, the researcher tests the fourth hypothesis for the differences between the control and experimental groups in the post measurement to test English speaking skills.

\section{Discussion:}

In the light of the previous results, it is clear that the pupils of the experimental group outperformed the control group in post-treatment. Pupils' oral performance increased after exposing them to different storytelling activities. This may be due to the fact that in narrative events, words are not memorized but are received through spontaneous energetic performances, assisted by audience participation (peers) and by interaction which involves the relationship between the narrator and the listener, in an interactive space of the performance. In storytelling, pupils are encouraged to join in repetitive sentences and have the opportunity to suggest variations in certain elements and aspects of the story. In digital storytelling, pupils use more repetitive phrases, sounds and gestures; chance that strengthens their imagination and encourages them to create a mental image of the elements of language . 
Storytelling can also be effective in teaching pupils about different ways of speaking. Through digital storytelling, EFL pupils become creative storytellers through the traditional processes of selecting a topic, researching, writing a screenplay, and developing an interesting story. Digital storytelling engages even reluctant pupils and inspires each pupil to do their best to present the story perfectly to the audience. They can be motivated and their oral skills and competences can be developed. The digital storytelling technique can be used effectively in the classroom to motivate speaking. The computer class surpassed the other in motivation and presentation. They presented stories using digital images, photographs, videos, animation, sound, music, text and a narrative voice that reinforced the positive motivating impression of the storytelling and allowed pupils to construct personal narratives of history. Simply put, by engaging digital storytelling, learning not only becomes personal, fun, engaging and creative, but it helps pupils improve their writing, reading, listening and speaking skills by learning to express opinions and speak.

The results of the present study also revealed that pupils in the experimental group, compared to the control group, were able to speak well after being exposed to different storytelling strategies. This may be because digital storytelling has improved fluency, vocabulary acquisition, and comprehension skills .

Despite the limitations of this study due to its small sample size and relatively short duration, this study has contributed to our knowledge of digital storytelling in 
relation to pupils' oral skills when learning to a foreign language. It showed that the interactive activities and the use of multimedia in the designed learning environment, combined with the use of digital storytelling, help to improve their speaking skills while learning English as a foreign language.

Most of TEFL research on digital storytelling to improve foreign language skills have isolated digital storytelling and studied it as an intervention tool. The results of the present study, which focused on the combined effect of a learning environment and a scaffolding for digital storytelling, confirm the results of previous studies based solely on digital storytelling .

Although the participants in the control group also experienced an increase in their speaking skills through traditional teaching, the progress made by the participants in the intervention group, who were those who used an interactive learning environment, were able to create digital stories, they were larger and the difference between the two groups was statistically significant .

The positive attitudes documented by participants in the intervention group can potentially be attributed to the fact that all activities were aimed at practicing only their oral speech and the learning experience was personalized and each participant worked at their own pace. . This result is in agreement with the recent study, in which pupils also perceived the benefits of personalized learning, achieved using technologies within the framework of foreign 
language learning through digital storytelling. The quizzes in the learning environment of this study provided immediate feedback, which may have helped participants not to repeat the same mistakes in their activities. In their last activity, the participants tried to avoid mistakes made during the conversation and tried to implement the rules that were presented to them at the start of their interaction with the learning environment of the participants of the experimental group in that their personal story was told in an interesting way, while being structured by the learning environment rather than by the teacher, as suggested by recent previous studies, in which teachers took on the role of guiding pupil learning in digital storytelling.

From the previous results, it can be concluded that digital storytelling is an effective strategy that incorporates the authentic ways of knowing a text into instruction. In addition to improving the performance in the areas of listening and speaking (oral language), digital storytelling has a great impact on second language learning. The effectiveness of digital storytelling may be due to merging a variety of activities and tasks that encouraged the pupils to develop their EFL oral proficiency. At the begging of the intervention, some pupils were not able to speak because of being afraid of negative assessment and making mistakes in pronunciation during speaking English. By using many activities such as role play, taking turns and oral discussion, the pupils' fear of participation decreased. It can be concluded that using digital storytelling was 
effective in developing the EFL speaking skill of the experimental group.

Digital storytelling is suitable tool for EFL majors of Education. Moreover, digital storytelling could be a means for increasing students' motivation to improve and practice their EFL writing and critical thinking skills. In this research, encouraging students to learn was defined as persuading students to participate in the activities, by making activities interesting for them, making them believe that they will be able to improve their EFL writing and critical thinking skills through DS and weblogs. An interesting instruction and activities in the classroom also can attract the student to participate teaching and learning in the classroom.

\section{Recommendations}

Based on the research results, the following recommendations are presented:

- Digital storytelling should be implemented in teaching EFL speaking skills to pupils at the primary stage.

- Teachers should be trained on the use of technology instead of traditional teaching.

- Teachers should provide pupils with different types of digital stories to watch and listen to extensively, not only the story they study in the curriculum.

- Schools should be provided with access to the internet inside the classrooms and use it in an effective way.

- Training teachers of English language on integrating digital storytelling instruction and weblogs while 
teaching English to their students in the early educational stages.

- English language teacher should emphasize the development of the students' narrative writing and critical thinking skills in the early educational stages to develop in the following stages.

- Curriculum designers should make use of integrating digital storytelling instruction and weblogs when designing English language courses.

\section{References}

- Abasi, M., \& Soori, A. (2014). Is storytelling effective in improving the English vocabulary learning among Iranian children in kindergartens? International Journal of Education \& Literacy Studies, 2(3), 7-12.

- Aprianto, D. \& Zaini, N. (2019). The Principles of Language Learning and Teaching in Communication Skill Developments. VELES Voices of English Language Education Society. Vol. 3. p. 45.

- Corbett, J. (2003). An intercultural approach to English Language Teaching. Clevedon, UK: Multilingual Matters.

- Cubukcu, F. (2014). A synergy between storytelling and vocabulary teaching through TPRS. International Association of Research in Foreign Language Education and Applied Linguistics. ELT Research Journal, 3(2), pp. 84-90.

- Goh, C.C.M. \& Burns, A. (2012). Teaching speaking: A holistic approach. New York: Cambridge University Press

- Pakula, H. M. (2019). Teaching speaking. Apples - Journal of Applied Language Studies, Vol. 13, p. 95.

- Robin, B. (2008). Digital Storytelling: A Powerful Technology Tool for the 21st Century Classroom, The College of Education and Human Ecology, The Ohio State University. 
- Brown, G., \& Yule, G. (1989). Teaching the spoken language: an approach based on the analysis of conversational English. Cambridge: Cambridge University press.

- Richards J. (2008). Teaching listening and speaking: From theory to practice. New York: Cambridge University Press.

- Katherine, O. C., (2017). What Students Do with Words: Language Use and Communicative Function in Full and Partial Immersion Classrooms, NABE Journal of Research and Practice.

- Jakes, D. S., \& Brennan, J. (2005). Capturing stories, capturing lives: An Introduction to digital storytelling.

- Sadik A., (2008). Digital storytelling: a meaningful technologyintegrated approach for engaged student learning. Educ Technol Res Dev 56(4), 487-506.

- Kosara, R., \& Mackinlay, J. (2013). Storytelling: The Next Step for Visualization. Computer, IEEE Computer Society, 46(5), 4450 .

- Nazuk, A.; Khan, F.; Munir, J.; Anwar, S.; Raza, S. \& Cheema, U. (2015). Use of digital storytelling as a teaching tool at national university of science and technology. Bulletin of Education and Research, 37(1), 1-26.

- Shelton, C. C., Archambault, L. M., \& Hale, A. E. (2017). Bringing Digital Storytelling to the Elementary Classroom: Video Production for Preservice Teachers. Journal of Digital Learning in Teacher Education, 33(2), 58-68.

- Emmett, M., Pollock, J., \& Komesaroff, L. (2003). Doing Things with Language. In Language and Learning: An Introduction for Teaching (pp. 21-47). Melbourne: Oxford University Press.

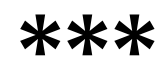

